\title{
CONTINUOUS MURMURS IN CYANOTIC CONGENITAL HEART DISEASE
}

\author{
BY \\ MAURICE CAMPBELL AND D. C. DEUCHAR \\ From the Cardiac Department, Guy's Hospital, and the Institute of Cardiology
}

Received December 3, 1960

\begin{abstract}
A continuous murmur resembling that of persistent ductus arteriosus is not rare in cyanotic congenital heart disease, and patients with such a murmur present a striking and interesting clinical picture. The simple explanation that it is due to a persistent ductus is sometimes correct, but more often it is due to the blood flow through enlarged bronchial arteries. We are reporting 45 examples of such patients with an undoubted continuous murmur -27 seen among our first 670 patients with cyanotic congenital heart disease $(4 \%)$ and 18 seen subsequently. Generally the murmur was easily heard and widely conducted, and in all but four it was one of the striking physical signs.

The group was certainly heterogeneous, but it seems worth giving a short clinical picture of the patients as a whole before attempting to divide them into groups. All were cyanotic by definition and nearly all had signs of right ventricular hypertrophy and a right ventricular pressure at about systemic level. Generally, the degree of cyanosis was not severe. In four patients it was very slight and three of these were originally sent up for ligation of a persistent ductus. In nearly half the others, it was only Grade 2, in one quarter it was Grade 3, and in a quarter it was severe (Grade 4). On the average, it was less severe than in Fallot's tetralogy (see Table III), and this was reflected in the number with only slight clubbing of the fingers and a relatively small increase in the hæmoglobin percentage, which was generally between 90 and 140 per cent $(100 \%=15 \cdot 6 \mathrm{~g}$. $)$.

Their disability, though varying widely and severe enough, was less than in most patients with morbus cœruleus, for most of them were in Grade 2 or 3, while with Fallot's tetralogy most are in Grade 3 or 4 (Table III). Squatting was found much less commonly than with Fallot's tetralogy. In spite of these findings many had very large hearts. In most there was a deep, sharply-defined pulmonary bay with a large "aortic" shadow, producing an exaggeration of the sabot-shaped heart (Fig. 1 and 6), though in others the heart was smaller with the appearance generally accepted as common in pulmonary atresia. Angiocardiography was of the greatest value in demonstrating the pathways of the blood flow to the lungs. In many of the groups with large hearts, there was little trace of any element of the pulmonary arterial system and the blood was carried by bronchial arteries (Fig. 2 and 7). In spite of this, the blood flow to the lungs was increased in several patients and we want to emphasize this group because it has not been widely recognized. There was a high incidence of a right-sided aortic arch.

Most of our patients have a solitary arterial trunk with the blood flow to the lungs through a persistent ductus, through hypertrophied bronchial arteries, or through other anomalous collateral arteries, but a few have Fallot's tetralogy. We propose to discuss first the anatomical criteria for distinguishing persistent truncus arteriosus (P.T.A.) and pulmonary atresia for this explains how we are classifying our patients. These two conditions have often been confused although Vierordt made the distinction between them as long ago as 1898 .
\end{abstract}



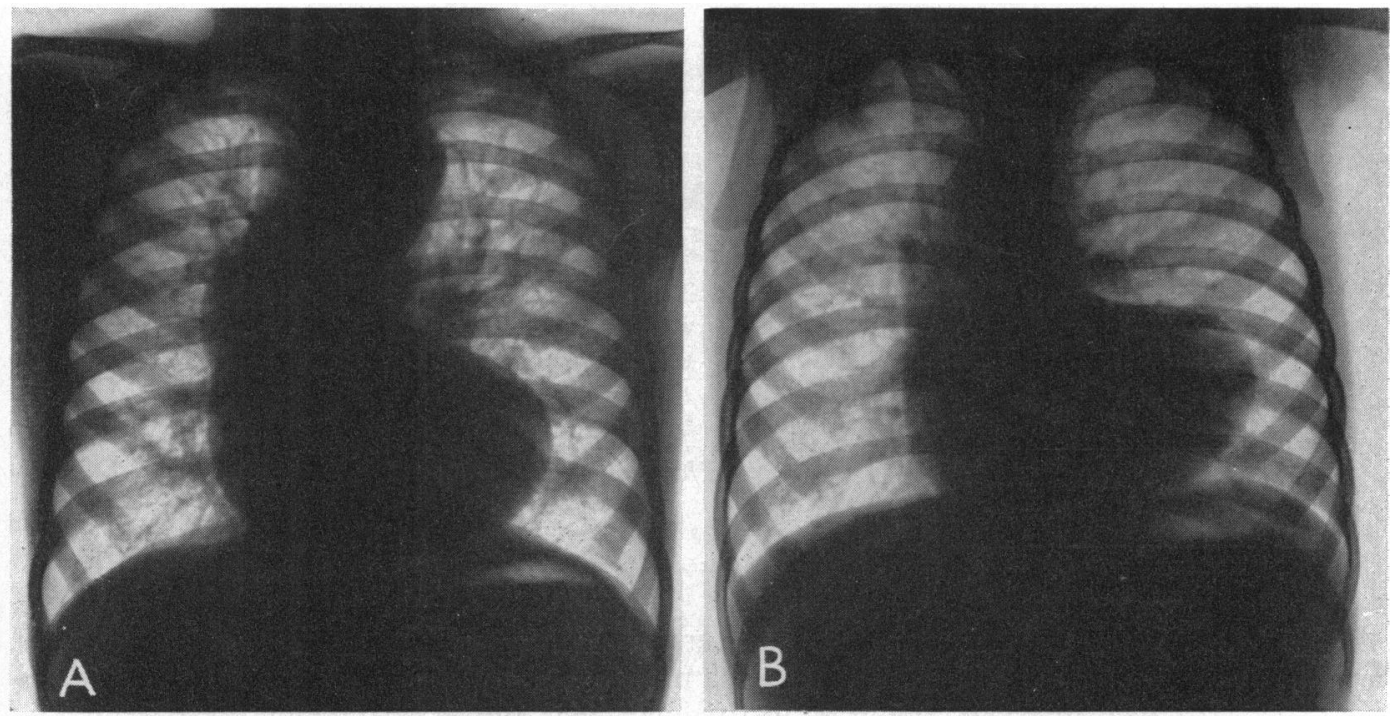

FIG. 1.-Teleradiograms of two patients showing large sabot-shaped hearts with a deepsharply-defined pulmonary bay and an increased blood flow to the lungs through bronchial arteries. (A) A boy, aged 7 in 1948: heart, c.t.r. 57 per cent; a very large solitary trunk with a left-sided aortic arch. Neither his clinical condition nor the size of his heart had changed much, 12 years later. Case 2. (B) A girl, aged 3 in 1949: heart, c.t.r. 59 per cent; a large solitary trunk with a right-sided aortic arch. She is not as well and is rather more disabled and more cyanotic in 1960: her heart is the same shape but smaller (c.t.r. 51\%). Case 10.
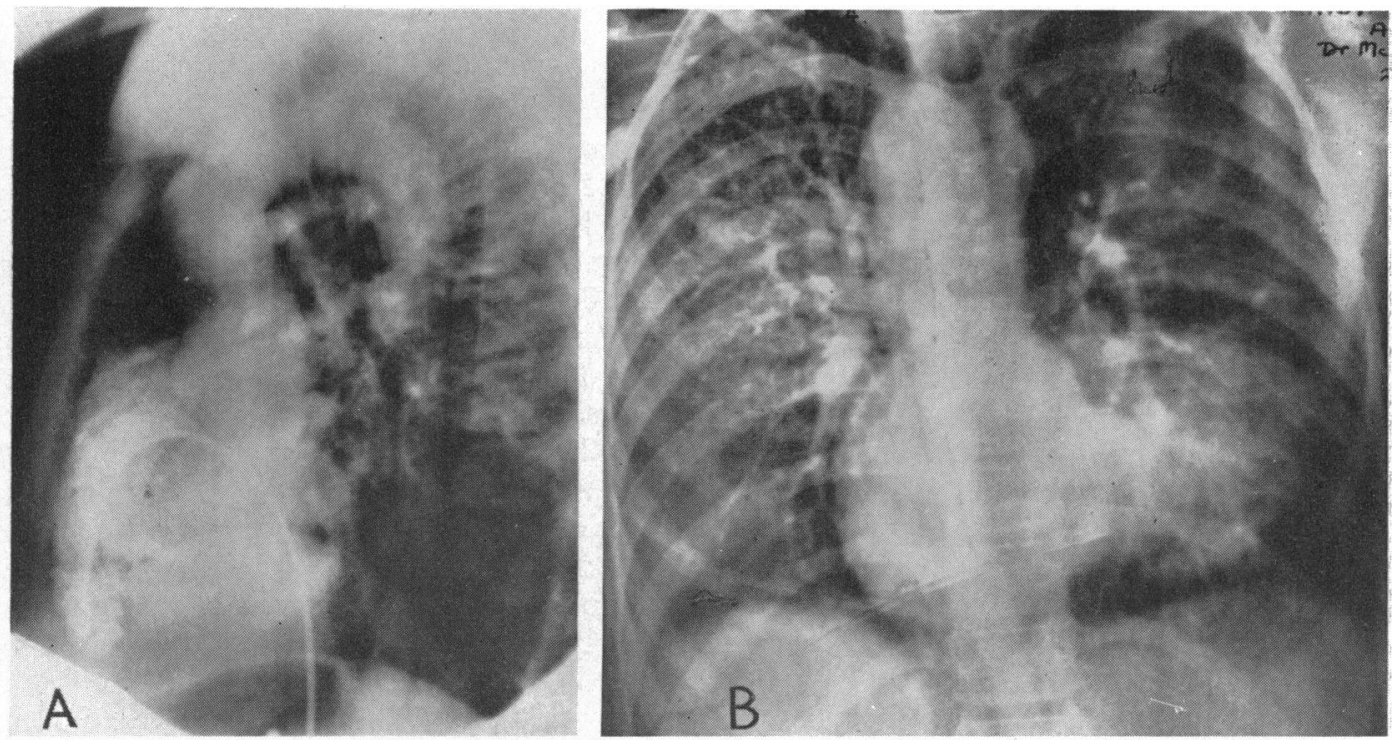

FIG. 2.-Angiocardiograms from the two patients whose hearts are shown in Fig. 1. (A) Left anterior oblique position after injection of opaque medium into the right ventricle. There is no trace of a pulmonary trunk, but bronchial arteries are well seen in the aortic window, arising just below the arch and lower from the descending aorta. Case 2, in 1960. (B) Showing absence of the pulmonary trunk and the characteristic nodular appearance of a bronchial artery blood supply to the lungs, possibly terminating in very small pulmonary arteries. Case 10, in 1951. 


\section{Persistent Truncus Arteriosus (P.T.A) and Pulmonary Atresia (Single Arterial TRUNK)}

For our understanding of the pathological anatomy we are indebted to the valuable papers of Humphreys (1938) and of Collett and Edwards (1949). The latter authors concluded that there are only two criteria essential for the diagnosis of P.T.A.: (1) there must be only the one common trunk leaving the base of the heart and no remnant of an atretic pulmonary trunk or aorta, and (2) this trunk must supply arteries to the coronary, systemic, and pulmonary systems. We agree with these criteria, but the second applies equally to the single trunk of pulmonary atresia. In practically every case of P.T.A. there is a defect of the ventricular septum, large enough in about one-fifth of the cases to produce a single ventricle: a defect is usual but less constant with pulmonary atresia. Though we have not accepted some of the smaller points in Humphreys' paper, the classification which we have used is based on her work.

When a solitary trunk has been demonstrated, the patient must belong to one or other of the groups I or III described below, but it may be impossible to decide which without anatomical proof from necropsy or operation: for such patients we have inserted Group II.

Group I. Persistent truncus arteriosus (Common arterial trunk). With complete absence of at least the first part of the pulmonary trunk, a very wide common trunk, sometimes with four semilunar cusps.

(A) With right and left pulmonary arteries arising direct from the truncus (Fig. 3, Ia).

(B) With bronchial arteries arising from the truncus and providing the only blood supply to the lungs (Fig. 3, Ib), generally without any derivatives of the sixth arch.

(C) Partial P.T.A, generally without but sometimes with a persistent ductus arteriosus, as shown in Fig. 3, $1 \mathrm{c}$.

Group II. Solitary arterial trunk. This group, essential in clinical practice though not a true anatomical one, has been subdivided according to the size of the blood flow to the lungs through the bronchial arteries.

(A) Those with an increased flow to the lungs.

(B) Those with a diminished flow to the lungs.

Group III. Single arterial trunk. Nearly always this is an aorta with pulmonary atresia, but rarely it may be a pulmonary trunk with an atretic aorta - a distinction that can be made only at necropsy.

(A) With a blood supply to the lungs through a persistent ductus to the right or left pulmonary artery (Fig. 3, IIIa).

(B) With a blood supply to the lungs through bronchial or other anomalous collateral arteries (Fig, 3, IIIb): these may often anastomose with small right and left pulmonary arteries.

Our Group IA is divided by Collett and Edwards (1949) into their types 2 and 3 (23 and 9 of their cases respectively), distinguished only by the lesser or greater degree of separation in position of the origin of the two pulmonary arteries. Our IB with bronchial arteries is their type 4 (10 cases). Our IC is their type 1 (their commonest form with 38 cases): though this is sometimes called "partial", the failure of development is just as complete at the ring, but in the lower part of the truncus a short pulmonary trunk is interposed between the truncus below and the two pulmonary arteries above. The blood supply to the lungs was generally through pulmonary arteries, but was through bronchial arteries in 10 and through a persistent ductus in 12 of their 80 cases.

It has been said that truncus arteriosus may be diagnosed only when there are four semilunar cusps to the common trunk: this we do not accept. Humphreys (1932) stated that "the surest landmark of the common trunk is the possession of four semilunar cusps, with two coronary arteries rising from the sinuses of opposite cusps," but agreed that "there may be numerous examples with but three cusps." In fact, Collett and Edwards found there were only two cusps in 1 case, three cusps in 49, four cusps in 9, and six cusps in 1 of their 60 cases. The four cusps were found most often in their type 1 . In any case, this point is of no use for clinical diagnosis. 

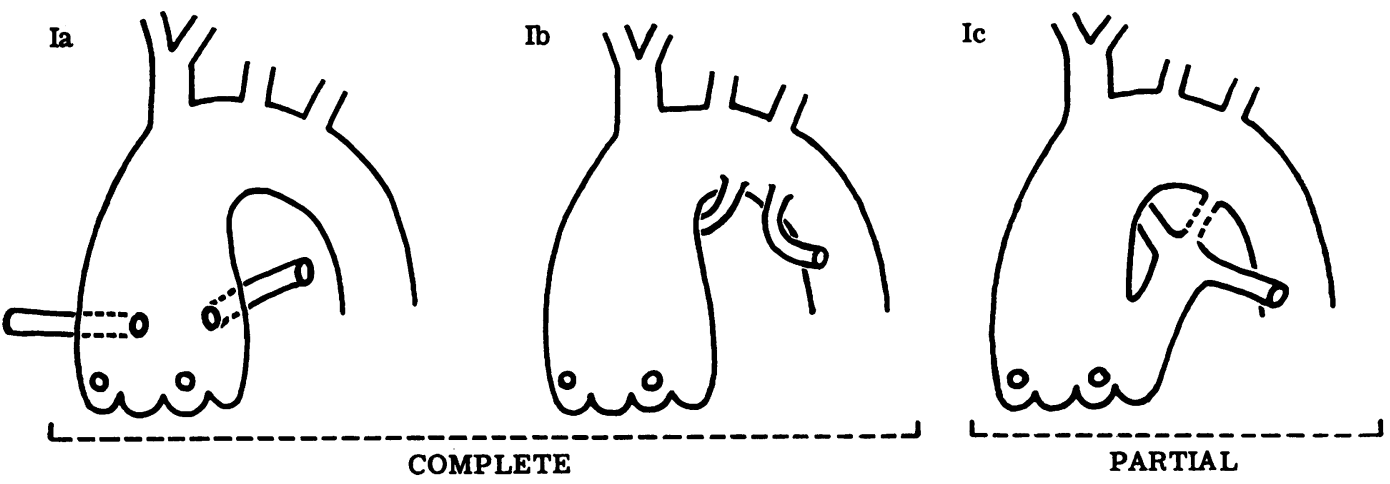

PULMONARY ATRESIA
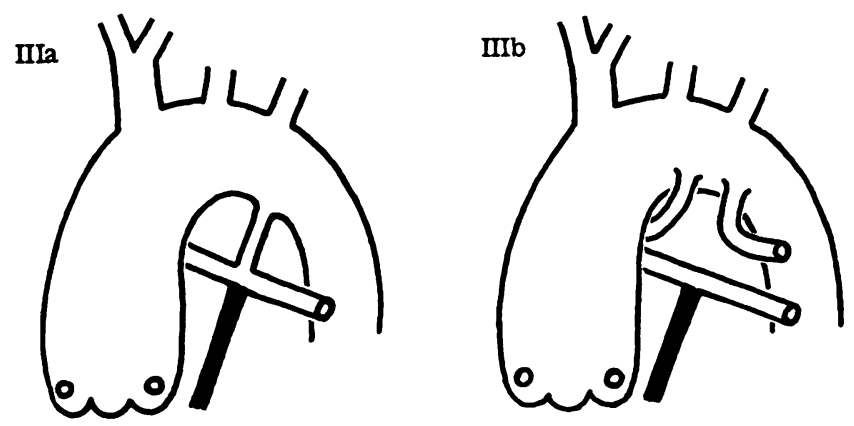

Fig. 3.-Diagrams of types of persistent truncus arteriosus (P.T.A.) (common arterial trunk) and of pulmonary atresia (single arterial trunk). We have drawn the four cusps in the diagrams of P.T.A. but do not accept these as an essential criterion for the diagnosis (see text). I. Persistent truncus arteriosus: (a) complete P.T.A., with two pulmonary arteries arising direct from the truncus; (b) complete P.T.A., with bronchial arteries arising from the truncus and no sixth arch derivatives: some cases are intermediate between these two varieties, having one pulmonary artery only and one or more bronchial arteries; and (c) partial P.T.A., generally without but occasionally with a persistent ductus arteriosus: this form can be distinguished from aortico-pulmonary septal defect only by the presence of a single arterial valve ring and of a ventricular septal defect. III. Pulmonary atresia with a single arterial trunk: (a) with a persistent ductus supplying the two pulmonary arteries; and (b) with bronchial or other collateral arteries arising from the aortic arch and generally with no easily recognizable derivatives of the sixth arch, though often these may be present beyond the atretic pulmonary trunk.

The Blood Flow to the Lungs. The diagnosis of truncus arteriosus may be easy if the pulmonary arteries are seen to arise from the truncus near their normal position, but more often the distinction from a single arterial trunk with pulmonary atresia is difficult and may be impossible in clinical practice, for they are functionally identical. Even at necropsy, it may sometimes take hours to find the atretic remnants of the pulmonary trunk. Humphreys (1932) thought that the way in which the artery entered the hilum of the lung was important in the differential diagnosis but derivatives of the sixth arch may be present in a partial or fairly complete form with persistent truncus and may be difficult or impossible to find except at necropsy in some cases of pulmonary atresia. When, however, as is often the case, only the first part of the pulmonary trunk is atretic, angiocardiography may reveal the small pulmonary arteries in continuity where they separate from the upper part of the pulmonary trunk. Such pulmonary arteries must, of course, be supplied with 
blood by anastomoses with arteries arising from the aorta, sometimes a persistent ductus but more often bronchial arteries. The general radiological features by which bronchial arteries can be recognized have been discussed by Campbell and Gardner (1950).

Ten years ago, we thought that an extremely wide trunk was evidence for a persistent truncus, although we realized that it was generally wide in pulmonary atresia. We do not now accept this distinction. The size of the aorta (like that of the individual chambers of the heart) depends mainly on the volume of the flow through it, and the hæmodynamic conditions are identical in truncus and in pulmonary atresia, for in both the systemic and the pulmonary flows must pass through the single trunk. As the systemic flow appears to be kept as near normal as possible in most forms of congenital heart disease (Brotmacher and Deuchar, 1956), the flow through a single trunk depends mainly on the size of the pulmonary flow, which varies much more widely. The important elements that we have tried to assess in each case are the size of this flow, which depends on the degree of development of the available arteries to the lungs, and the presence of some part of the pulmonary arteries, which are often very underdeveloped beyond the atresia but in their normal position.

\section{Classification of our Patients}

Of our 45 patients, 35 had an absent or atretic pulmonary trunk with the blood supply to the lungs through a persistent ductus, through hypertrophied bronchial arteries, or through other collateral arteries. Only 1 was proved to have persistent truncus arteriosus (Group I), 16 had a solitary trunk where the evidence was insufficient to decide between the single trunk of pulmonary atresia or the common trunk of P.T.A. (Group II), and 18 had pulmonary atresia with a single aortic trunk (Group III). Of the remaining 10 patients, 5 had Fallot's tetralogy or a related lesion (Group IV) and 5 had varied and complex lesions that were difficult to classify (Group V). In 1950 when Gardner reported the 15 of these cases that had then been fully investigated to the First World Congress of Cardiology, a higher proportion ( 3 of the 15) were diagnosed as P.T.A. but we have given reasons for being less sure of this.

\section{Group I. Persistent Truncus Arteriosus}

\section{IA. With Pulmonary Arteries Arising directly from the Truncus}

We have seen three patients with this condition but they are not included for none had a continuous murmur. The diagnosis was made at operation in one and was confirmed at necropsy in the other two. Of these last two, a girl, aged 9 when she died after thoracotomy, had a single atrium, a single ventricle, and isolated dextrocardia. She had severe cyanosis and, as might be expected, the pulmonary arteries, which arose directly from the truncus, were small-only $5 \mathrm{~mm}$. in diameter. The other, a girl aged 4 when she died, had had recurrent congestive heart failure for three years, and an exploratory thoracotomy, at which the diagnosis was made. Her persistent truncus, $3 \mathrm{~cm}$. in external diameter, arose in the mid-line above a ventricular septal defect, and two large pulmonary arteries arose from the truncus, $1 \mathrm{~cm}$. above the valve.

\section{IB. With Bronchial Arteries Providing the only Blood Supply to the Lungs}

Case 1. A boy, aged 3, had moderate disability and slight cyanosis from the age of two months, and had talipes also. There was no history of squatting. He had a continuous murmur, equally well heard on both sides under the clavicles and posteriorly, and a soft systolic ejection murmur as well. The heart was large (c.t.r. 58\%) and sabot-shaped with a deep pulmonary bay (Fig. 4A), and showed right ventricular hypertrophy. The aortic arch was right-sided and the lung fields were oligæmic. He died after angiocardiography.

At necropsy, there was a common trunk, with three semilunar cusps, arising entirely from the right ventricle though there was a large high ventricular septal defect. No evidence of an atretic pulmonary trunk could be found. The blood supply to the lungs was through three large bronchial arteries-one arising near the usual site of the ductus and supplying the right upper lobe, and the other two arising from the anterior aspect of the descending aorta and supplying the right lower lobe and all the left lung respectively. These are shown well in the angiocardiogram (Fig. 4B): although large, they were not as large as normal pulmonary arteries. The foramen ovale was unsealed, but there was no other cardiac malformation. 

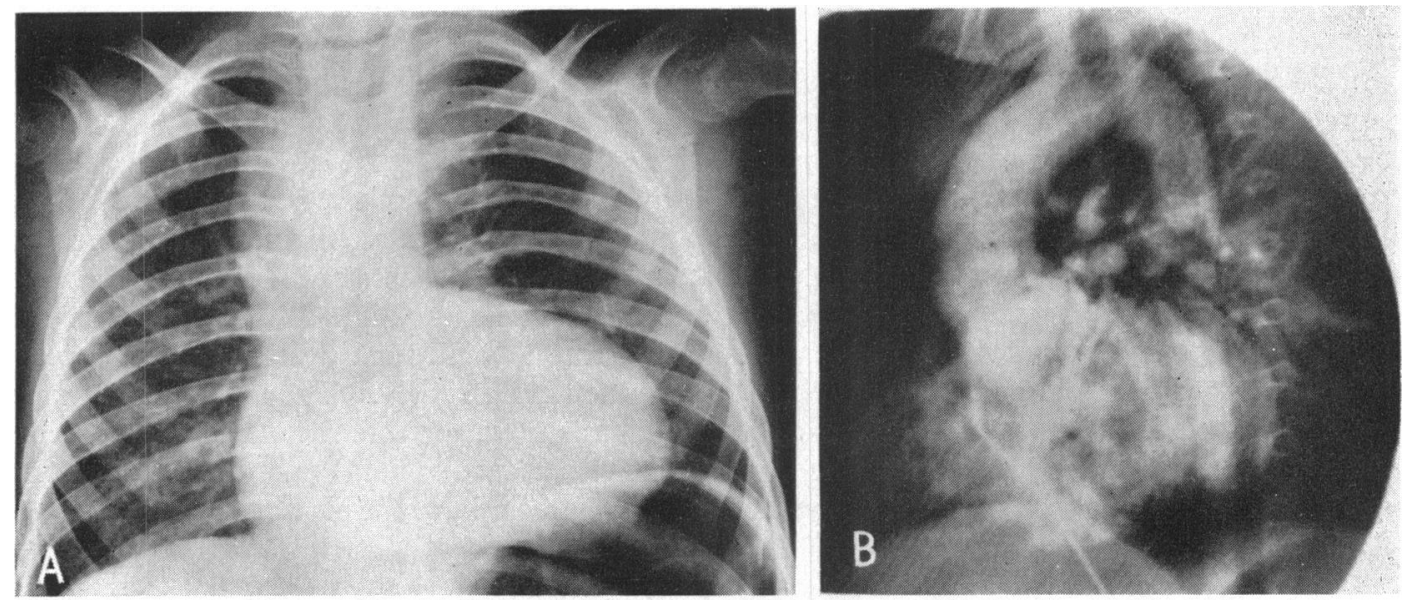

FIG. 4.-From a boy, aged 3, with persistent truncus arteriosus, proved by necropsy. (A) Teleradiogram, showing an extreme sabot-shaped heart with a sharply-angled pulmonary bay and a right-sided aortic arch. (B) Angiocardiogram in the left anterior oblique position, showing the large common trunk filling from the right ventricle, and bronchial arteries in the aortic window. The upper group of shadows is a bronchial artery that rose below the arch and supplied the right upper lobe. The lower group consists of two bronchial arteries that rose close together from the descending aorta, one supplying the right lower lobe and the other all the left lung. Case 1.

\section{Group II. Solitary Arterial Trunk (16 Cases)}

We have divided this group into (A) those where the pulmonary blood flow was increased (9 cases) and (B) those where it was diminished (7 cases), because this difference is so important. The disability and cyanosis were inversely related to the size of the blood flow so these will be discussed separately, but several features were shared by both sub-groups and some of these by the patients with pulmonary atresia, so these features will be discussed first.

In none of the 34 patients with a solitary trunk or with pulmonary atresia was there any evidence of a direct communication between a ventricle and a pulmonary trunk, even if the upper part of this was present, and in 29 of them this was confirmed by angiocardiography. In none of the 23 who had catheterization was it possible to enter the pulmonary trunk. The right ventricular pressure was about the same level as the systemic pressure and there was evidence of right ventricular preponderance on radioscopy and cardiographically.

The electrocardiograms are hardly mentioned because nearly all of them showed right axis deviation and right venticular preponderance, resembling those seen in Fallot's tetralogy. The P wave in lead II was sometimes rather large and pointed, but neither this, nor deep $\mathrm{T}$ inversion in the right chest leads, was seen as often or as strikingly as in the more severe cases of simple pulmonary stenosis. The blood pressure was not remarkable and was with one exception (Case 8 ) in the low normal range found in most children and young adults.

In the 16 who had a solitary trunk, the second sound was always single and often loud in the pulmonary area. The continuous murmur was generally conducted widely to both sides and to the back, and was often heard best on the right side ( see p. 187): a thrill was nearly always felt in systole and was felt in diastole also in 8 of the 14 cases where we have adequate notes.

In none of these 16, was there any evidence of a persistent ductus. The blood flow to the lungs was thought to be through bronchial or other anomalous arteries in all 16 cases. Generally this diagnosis was made on the shadows seen on angiocardiography or radioscopy, especially in the aortic window (Fig. 2A and 7B) or on the irregular nodular shadows spreading out from the hila of the lungs (Fig. 2B and 5A). It is difficult to say much about the anatomical arrangements 

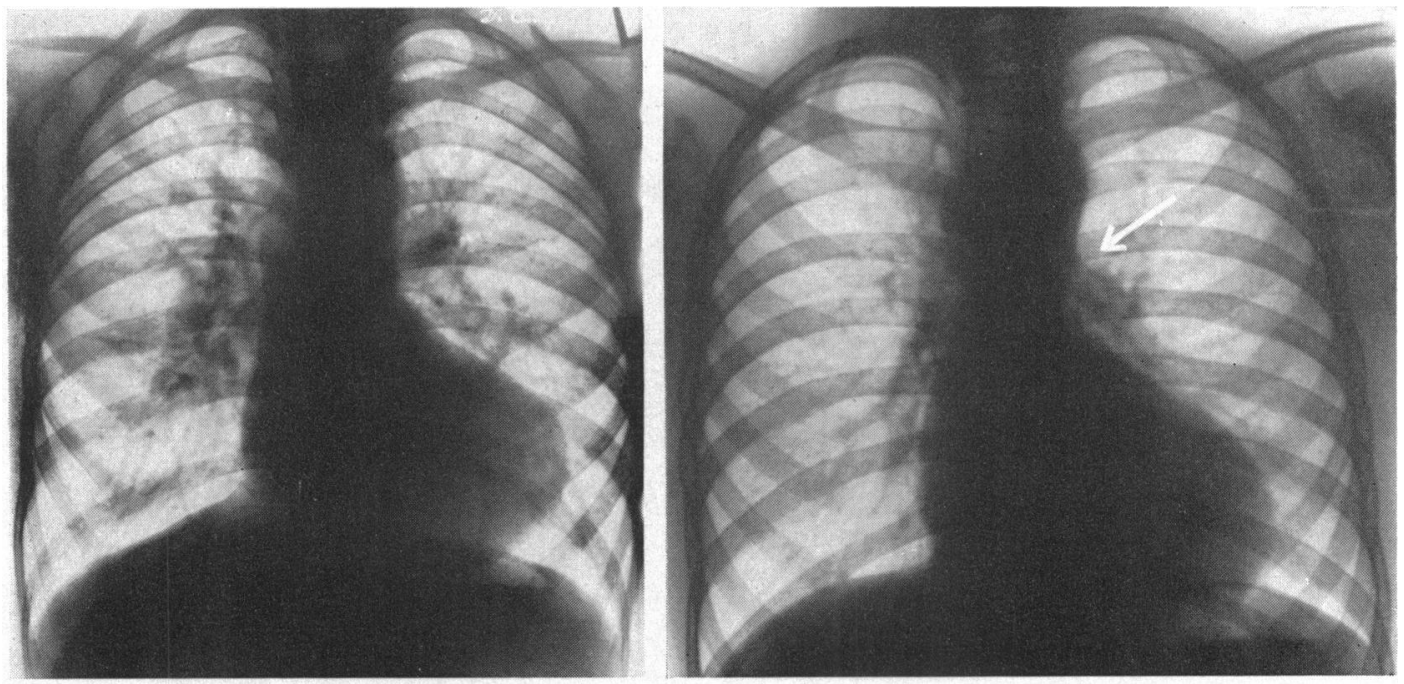

FIG. 5.-Teleradiograms from two patients with a solitary trunk and an increased blood supply to the lungs through bronchial arteries. Group IIA. (A) From a boy, aged 7, showing a large heart (c.t.r., 55\%), a sharply-defined but not very deep pulmonary bay, and nodular hilar markings. He has got on well for 12 years. Case 5. (B) From a girl, aged 12. At first sight there appears to be a large left pulmonary artery but the upper part (marked by an arrow) is sloping upwards and not horizontally like a normal pulmonary artery: angiocardiography confirmed that it was a bronchial artery. Twelve years later, her main disability is caused by obesity. Case 6.

of bronchial arteries except in cases that have come to necropsy, and we have already described and illustrated several examples of these in pulmonary atresia (Allanby et al., 1950). A large artery of unusual shape was seen in three patients (Cases 5 (Fig. 7A), 7, and 13) and we think these were bronchial arteries, and have no doubt that they were in the others: the aortic window seemed almost filled by large bronchial arteries in Case 9 with the largest pulmonary flow. Perhaps the commonest finding is three larger bronchial arteries with numerous smaller anastomoses from various sites. Few showed any trace of what might have been pulmonary arteries or at the most only a thin vessel going into the hilum of the lung that might have been the termination of a bronchial artery or one of these anastomosing with the remnants of a pulmonary artery.

The heart was moderately or greatly enlarged in every patient but one (Case 13, proved by necropsy, c.t.r. $47 \%$ ), the average cardiothoracic ratio (c.t.r.) being 58.4 per cent. Characteristically, it showed an exaggeration of the sabot shape with a deep pulmonary bay (Fig. 1 and 6), generally with an unusually sharply-defined edge (Fig. 1 and 5A) due to the absence of any pulmonary artery continuous with the outline of the heart and solitary trunk. In a quarter of them the pulmonary bay had a sharp angle as well as being deep. In Case 6 the heart shadows seemed to have a more ordinary shape because a large bronchial artery filled part of the pulmonary bay but sloped upwards towards the trunk instead of horizontally like a pulmonary artery (Fig. 5B).

The solitary trunk was large in all but 3 , and specially large in 6 of the 16 . Sometimes this modified the characteristic sitting-duck shape (Fig. 1 and 6) and made it rather similar to the large heart and dilated aorta seen with syphilitic aortic regurgitation.

\section{IIA. With an Increased Blood Flow to the Lungs}

The 9 patients in this group are in many ways the most interesting, for the possibility of an increased blood flow to the lungs through bronchial arteries has not, we think, been recognized. Patients with truncus arteriosus who have done so well for so long or with pulmonary atresia and 

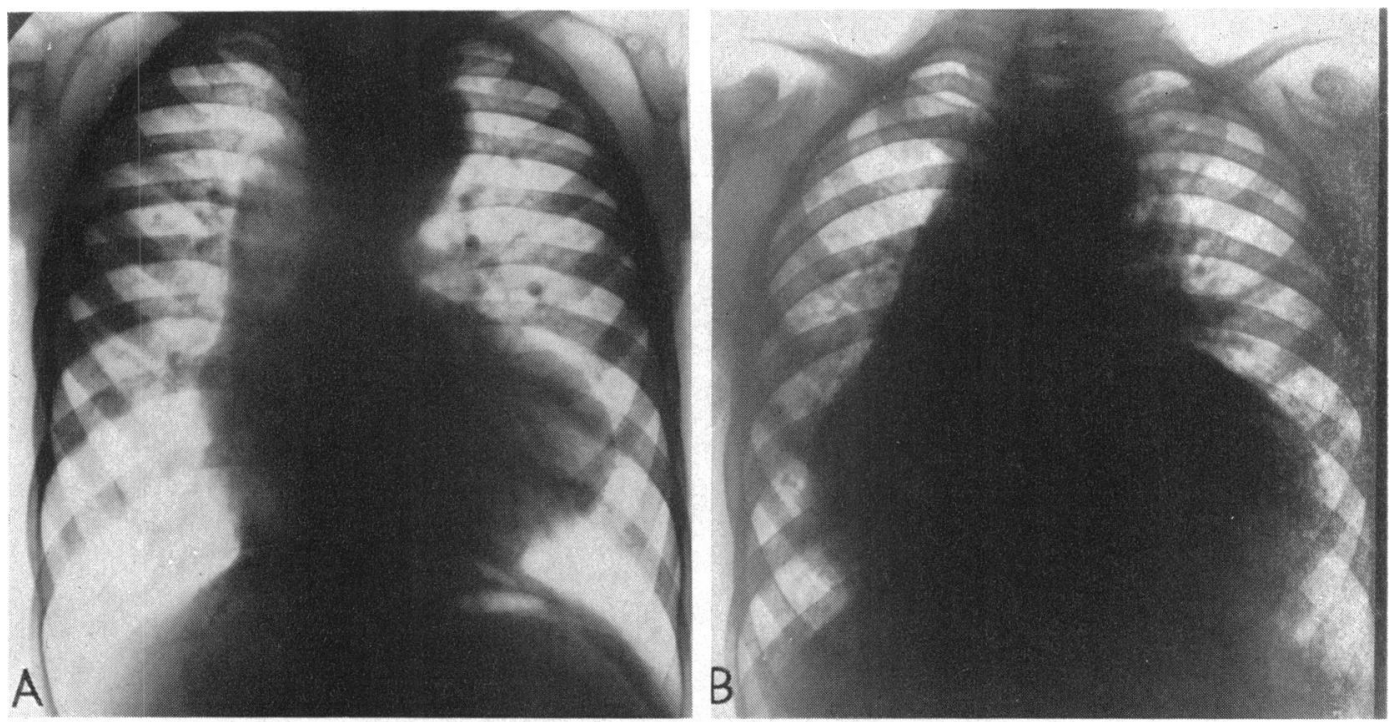

FIG. 6.-Teleradiograms from a patient with a solitary trunk, a large heart, and an increased blood flow to the lungs through bronchial arteries. Case 9. (A) In 1949, when he was 7 and had little disability; c.t.r., 66 per cent. The increased blood flow does not show well in the print and the film has been lost. (B) In 1959, when he was making a good recovery from congestive heart failure, c.t.r., 82 per cent.
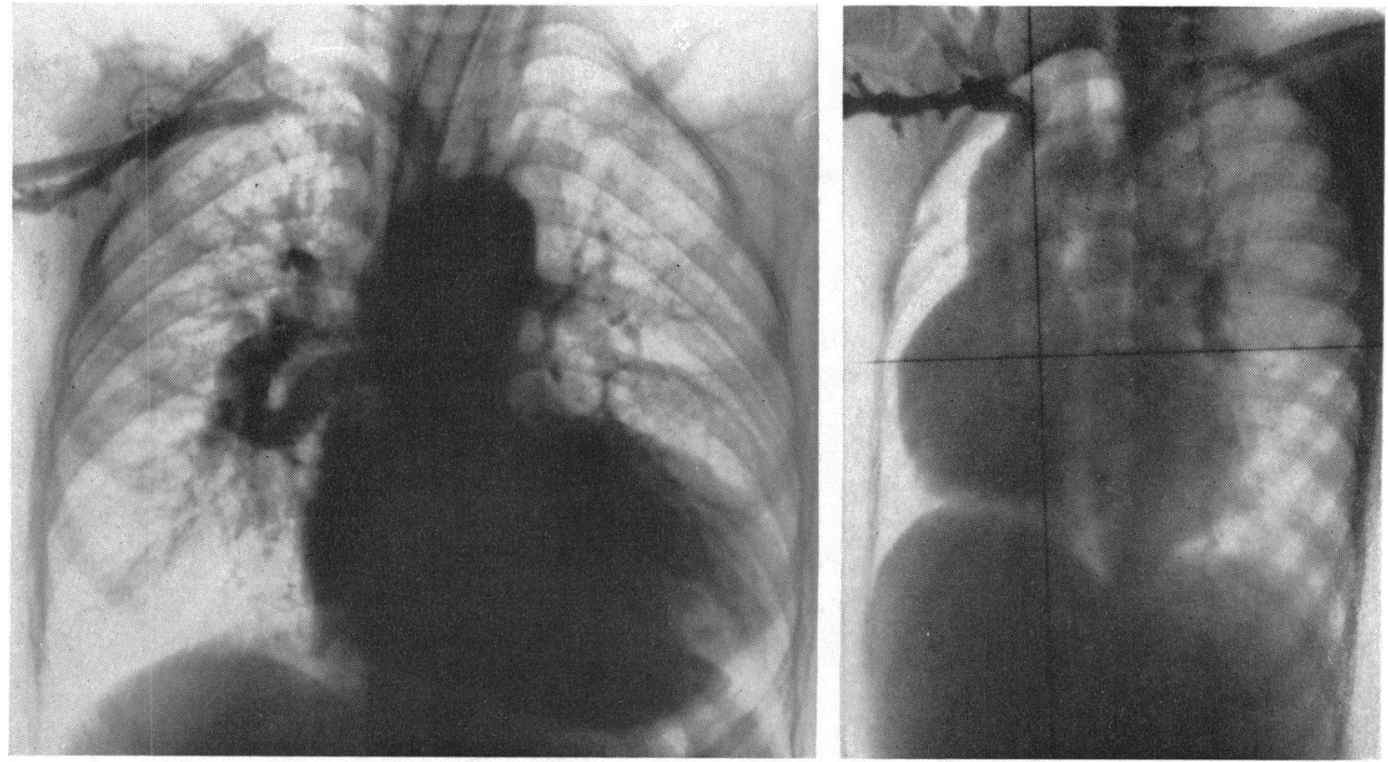

FIG. 7.-Angiocardiograms from two patients with a solitary trunk and an increased blood supply to the lungs through bronchial arteries. Group IIA. (A) From a boy, aged 7, showing several bronchial arteries, the one on the right being specially large and curiously shaped. See also Fig. 5A. Case 5. (B) From a girl, aged 6, showing several bronchial arteries filling much of the aortic window and passing downwards and especially to the left. She has got on well for 12 years. Case 3. 
an increased pulmonary blood flow have not often been reported; yet these 9 must belong to one or other of these groups though we do not know which.

Our patients, about whom some clinical details are given in Table I, were moderately disabled, quite enough to make them wish for surgical treatment if this were available, but less than most cyanotic children. Most of them could walk $\frac{1}{2}$ a mile or more: two (Cases 4 and 9) could do much more than this but Case 10 was more disabled.

TABLE I

Clinical Data for Patients with a Solitary Trunk and an Increased (above) or Diminished (below) Pulmonary Blood Flow through Bronchial Arteries

\begin{tabular}{|c|c|c|c|c|c|c|c|c|}
\hline Case No. & Sex and age & Disability & Cyanosis & Clubbing & $\begin{array}{c}\text { Hb. } \\
\text { percentage }\end{array}$ & Squatting & $\begin{array}{l}\text { Heart size } \\
\text { (c.t.r.) }\end{array}$ & $\begin{array}{l}\text { Aortic } \\
\text { arch }\end{array}$ \\
\hline $\begin{array}{r}2 \\
3 \\
4 \\
5 \\
6 \\
7 \\
8 \\
9 \\
10\end{array}$ & $\begin{array}{l}\text { M } 7-19 \\
\text { F } 6-18 \\
\text { F24-29 } \\
\text { M } 7-18 \\
\text { F12-24 } \\
\text { F13 } \\
\text { F17-30 } \\
\text { M } 6-17 \\
\text { F } 2-14\end{array}$ & $\begin{array}{l}2 \\
2- \\
1 \\
2 \\
3- \\
2 \\
2+ \\
2- \\
2-\end{array}$ & $\begin{array}{l}2- \\
2- \\
2 \\
2 \\
2+ \\
1 \\
2- \\
1 \\
2-\end{array}$ & $\begin{array}{l}2 \\
1 \\
0 \\
1 \\
2 \\
1 \\
2 \\
0 \\
2\end{array}$ & $\begin{array}{r}118 \\
92 \\
96 \\
110 \\
107 \\
98 \\
109 \\
94 \\
108\end{array}$ & $\begin{array}{l}\text { No } \\
\text { No } \\
\text { Yes } \\
\text { No } \\
\text { No } \\
\text { No } \\
\text { No } \\
\text { No } \\
\text { No }\end{array}$ & $\begin{array}{l}58 \\
66 \\
68 \\
55 \\
56 \\
56 \\
65 \\
58\end{array}$ & $\begin{array}{l}\mathbf{L} \\
\mathbf{R} \\
\mathbf{R} \\
\mathbf{L} \\
\mathbf{L} \\
\mathbf{R} \\
\mathbf{R} \\
\mathbf{L} \\
\mathbf{R}\end{array}$ \\
\hline $\begin{array}{l}11 \\
12 \\
13 \\
14 \\
15 \\
16 \\
17\end{array}$ & $\begin{array}{l}\text { M } 7-16^{*} \\
\text { F } 4-15 \\
\text { M12-19* } \\
\text { F } 7-10 \\
\text { F10-19* } \\
\text { F10 } \\
\text { F30* }\end{array}$ & $\begin{array}{l}3- \\
2+ \\
2 \\
3 \\
3 \\
- \\
2-4\end{array}$ & $\begin{array}{l}2 \\
2 \\
2 \\
4 \\
3 \\
3 \\
4\end{array}$ & $\begin{array}{l}4 \\
3 \\
4 \\
4 \\
3 \\
4\end{array}$ & $\begin{array}{l}134 \\
110 \\
112 \\
161 \\
118 \\
-\overline{149}\end{array}$ & $\begin{array}{l}\text { Yes } \\
\text { No } \\
\text { No } \\
\text { Yes } \\
\text { No } \\
\overline{\text { No }}\end{array}$ & $\begin{array}{l}62 \\
62 \\
47 \\
54 \\
56 \\
56 \\
56\end{array}$ & $\begin{array}{l}\mathbf{L} \\
\mathbf{R} \\
\mathbf{L} \\
\mathbf{L} \\
\mathbf{R} \\
\mathbf{L} \\
\mathbf{R}\end{array}$ \\
\hline
\end{tabular}

* Died

The two ages in column 2 represent the ages when the patient was seen for the first and last times.

+ and - in columns 3 and 4 represent some way above or below the average of the group.

Nor was their cyanosis severe. Most of them were put in grade 2, i.e. cyanosis that might not be noticed at a casual glance. Correspondingly, there was no great increase in their polycythæmia or hæmoglobin percentage, which ranged between 92 and 118 and averaged only 104 per cent. The clubbing of the fingers and toes was also correspondingly mild, being described as slight in four, trivial in two, and absent in two. Even in the most severe case there was no broadening of the finger ends.

Again as might be expected, they rarely squatted. Only the fit young woman of 24 (Case 4) said that she had done so till she was 8 years of age, so we wonder if her bronchial arteries may not have become larger during her early years of life.

All of them had large hearts, and the size of the heart and of the trunk and the unusual shape were all exaggerated by the increased pulmonary flow, the cardiothoracic ratio being larger (c.t.r. average $60.2 \%$, range 55 to $68 \%$ ) than in those where the flow was diminished (c.t.r., average $56 \%$, range 47 to $62 \%$ ). The lung fields were not grossly pleonæmic, and this could hardly be expected when the pulmonary flows were only about twice the normal.

At cardiac catheterization, which was performed in 6 of the 9, the pulmonary trunk was not entered in any and the aorta was entered from the right ventricle in 4 of them. The right ventricular pressure was equal to the aortic or the systemic arterial pressure recorded at the same time in all of them. The arterial oxygen saturations were all above 78 per cent, (mean, $83 \%$ ), reflecting the mild degree of cyanosis observed clinically. The essential figures of blood oxygen analysis are given in Table II. In Case 6 the mixed venous blood sample from the right atrium had a very low oxygen saturation, but this may be an error, due to sampling of coronary sinus blood. With this 
exception, the results are remarkably uniform for all six patients. The pulmonary flow was generally about twice the systemic flow and exceeded it in every case.

The following three short case notes are representative of this group.

TABLE II

Results of Cardiac Catheterization in Patients with a Solitary Trunk and an Increased PulMONARY BloOd Flow (Group IIA)

\begin{tabular}{|c|c|c|c|c|c|c|c|}
\hline \multirow{2}{*}{ Case No. } & \multicolumn{2}{|c|}{ Systemic artery } & \multicolumn{2}{|c|}{ Mixed venous blood } & \multicolumn{2}{|c|}{ A-V $\mathrm{O}_{2}$ differences } & \multirow{2}{*}{$\begin{array}{c}\mathrm{P} / \mathrm{S} \text { flow } \\
\text { ratio }\end{array}$} \\
\hline & $\% \mathrm{O}_{2}$ satn. & $\begin{array}{c}\mathrm{O}_{2} \text { content } \\
\text { (Vol. \%) }\end{array}$ & $\% \mathrm{O}_{2}$ satn. & $\begin{array}{c}\mathrm{O}_{2} \text { content } \\
(\text { Vol. } \%)\end{array}$ & Systemic & Pulmonary & \\
\hline $\begin{array}{r}2 \\
3 \\
6 \\
8 \\
9 \\
10\end{array}$ & $\begin{array}{l}78 \cdot 6 \\
83 \cdot 5 \\
78 \cdot 8 \\
83 \cdot 8 \\
89 \cdot 0 \\
83 \cdot 2\end{array}$ & $\begin{array}{l}18 \cdot 9 \\
14 \cdot 9 \\
17 \cdot 7 \\
16 \cdot 4 \\
16 \cdot 3 \\
17 \cdot 5\end{array}$ & $\begin{array}{l}58 \cdot 5 \\
60 \cdot 5 \\
38 \cdot 0 \\
66 \cdot 2 \\
65 \cdot 0 \\
61 \cdot 3\end{array}$ & $\begin{array}{r}13.4 \\
10.8 \\
8.6 \\
13.0 \\
11.9 \\
12.9\end{array}$ & $\begin{array}{l}5 \cdot 5 \\
4 \cdot 1 \\
9 \cdot 1 \\
3 \cdot 4 \\
4 \cdot 4 \\
4 \cdot 6\end{array}$ & $\begin{array}{l}3 \cdot 1 . \\
2 \cdot 2 \\
3 \cdot 9 \\
2 \cdot 4 \\
1 \cdot 3 \\
2 \cdot 7\end{array}$ & $\begin{array}{l}1.8 \\
1.9 \\
2.3 \\
1.4 \\
3.4 \\
1.7\end{array}$ \\
\hline 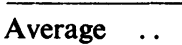 & $82 \cdot 8$ & $17 \cdot 0$ & $58 \cdot 3$ & $11 \cdot 8$ & $5 \cdot 2$ & $2 \cdot 6$ & $2 \cdot 1$ \\
\hline
\end{tabular}

Systemic arterial blood was derived either from catheterization of the aorta or puncture of a systemic vessel. Blood withdrawn from the right atrium has been used as representative of mixed venous blood. Pulmonary/systemic arterio-venous oxygen differences are calculated on the assumption that pulmonary venous oxygen saturation was 96 per cent.

Case 2. A boy, aged 7*, had been slightly cyanosed from the age of four months: he could walk half a mile but less in cold weather. He had a loud single second sound in the pulmonary area and a continuous murmur, maximal at the same site but nearly as loud on the right side and on both sides behind. The heart was large (c.t.r. $57 \%$ ) with a deep pulmonary bay and a wide "aorta" giving an exaggerated sabot shape (Fig. 1A). No pulmonary arteries were seen and the blood flow to the lungs was through bronchial arteries (Fig. 2A). He got on well for 12 years: he is doing light work and can walk 2 miles or cycle 10 miles.

Case 8. A girl, aged 17, was moderately disabled, but could walk up to a mile slowly. She had a large heart with a deep pulmonary bay. Her blood pressure in the right arm was often 140/90, but lower in the left arm and higher in the legs: there was no evidence of coarctation of the aorta although she had unilateral rib-notching on the right side (Fig. 5, Campbell, 1958), perhaps because of anastomoses between an enlarged intercostal artery and the lung, via the pleura. Her condition has changed little during 12 years.

Case 9. A boy, aged 6, had been slightly cyanosed from three months old but could walk a mile easily. He had the usual signs but was one of the few patients with hypertrophy of both ventricles and lungs that were obviously pleonæmic on radioscopy though this does not show well in Fig. 6A: he had the largest pulmonary flow of all these patients (see Table II). In 1959, when he was 17, he was re-admitted with congestive heart failure and a still larger heart (c.t.r. 82\%, Fig. 6B) but he had been leading a much more active life than advised, with hard manual work. He recovered and has remained well for another year with easier work.

\section{IIB. Solitary Trunk with a Diminished Blood Flow to the Lungs.}

Our main reason for separating these 7 patients from Group III is that investigations, including thoracotomy in 2 and angiocardiography in 5, revealed little or no evidence of the pulmonary arterial system. They were more disabled than those in Group IIA and were more often placed in grade 3 than in grade 2 . They were also more cyanotic though three were still in grade 2 . The arterial $\mathrm{O}_{2}$ saturation averaged 68 per cent (range 65-73) in the four where this was determined, instead of 83 per cent in those with an increased flow. Correspondingly, the hæmoglobin percentage was higher, averaging 130 (range 98 to $161 \%$ ), and all of them had moderate clubbing of the fingers. More of these patients, but still only 2 of them, squatted.

One (Case 16) was diagnosed earlier as having a persistent truncus (Fig. 3 and 4, Campbell and

* Unless stated otherwise, the age given is the age when the patient was first seen. 


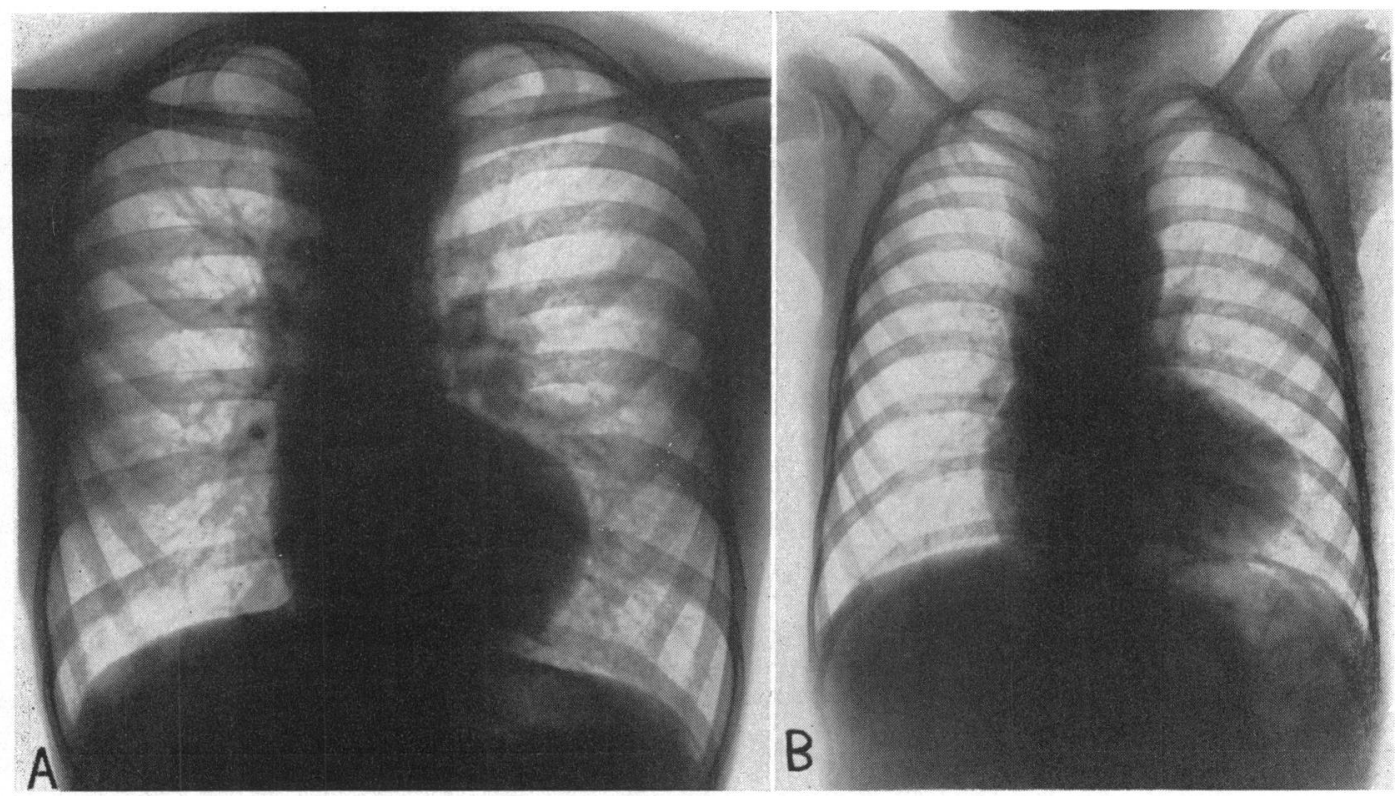

FIG. 8.-Teleradiograms of two patients with a solitary trunk and a diminished blood supply to the lungs through bronchial arteries. (A) From a boy, aged 12, showing no trace of normal pulmonary arteries, nodular shadows in the left lung, a double aortic arch, and a heart of normal size (c.t.r. $47 \%$ ). See text for necropsy. Case 13. (B) Showing no trace of pulmonary arteries, nodular shadows in the lungs, and a large heart (c.t.r. 61\%) from a boy, aged 7 . Case 11 .

Gardner, 1950), but now we think it better to place her in this more inclusive group. Three have died, but only Case 13 had a necropsy and we are still uncertain if he had truncus arteriosus.

Case 13. A boy, aged 12, was thought to have pulmonary atresia or possibly persistent truncus, though there was no increase in the size of his heart (Fig. 8A). The presence of a left-sided aortic arch and of a smaller right-sided arch from which an anomalous artery descended rather vertically to the right lung had been diagnosed by angiocardiography and confirmed at thoracotomy (Fig. 12, Campbell and Hills, 1950, and Fig. 6, Campbell and Gardner, 1950). Subsequently he was admitted to another hospital several times for paroxysms of tachycardia but his final admission, seven years later, was for severe pain in the left chest. This was due to a pneumo-hydro-thorax which became infected, and he died six weeks later, despite treatment with antibiotics.

At necropsy he had an encysted empyema of the left lung. No pulmonary trunk was found, and the solitary trunk divided into two, each division giving off to the lung on that side a large vessel that was thought to be a bronchial artery. The two divisions passed on either side of the trachea and osophagus and after doing so united to form the descending aorta. There was a ventricular septal defect. The diagnosis of truncus arteriosus seems probable, but we are not certain, because the search for an atretic pulmonary trunk may not have been thorough enough.

\section{Pulmonary Atresia}

The 18 patients placed in this group all had some elements of the pulmonary arterial systemenough to prove or to make us think that there was a pulmonary trunk even if it was wholly or partly atretic. The diagnosis of pulmonary atresia was proved in 11 cases, by necropsy in 5 (Cases 18-22) and by operation in 6 (Cases 23-28). As the remaining 7 (Cases 29-35) showed the same general features, including the results of angiocardiography, we are discussing them together.

There was only one proved example of the less common type of pulmonary atresia with a closed ventricular septum (Case 18) but Case 29, a girl aged 4, was accepted as a second example. This type seems to be less common than has been thought and among 14 necropsies of our cases there has been only one example (Campbell, 1960). Keith et al. (1958) call this type pulmonary atresia 
with normal aortic root and emphasize the frequency of a simple valvular occlusion that would be amenable to surgical treatment.

The blood supply to the lungs was thought to be through a persistent ductus in 5 (certain in 4, probable in 1) and through bronchial arteries in 10 (certain in 7, probable in 3): in one of the last (Case 20) it was through an anomalous artery as well. Of the remaining 3 it was through an anomalous artery in one and was uncertain in two.

Of these 18 patients, 16 were moderately or severely disabled and cyanosed (see Table III), with hæmoglobin percentages ranging from 110 to 148 (average $127 \%$ ), but 2 had relatively little disability and cyanosis. Only 4 of the 18 gave a history of squatting.

Often in pulmonary atresia, as in Fallot's tetralogy, the heart is little, if at all, enlarged (Fig. 9). This was so in 11 of these 18, the cardiothoracic ratio being between 46 and 53 per cent (average $49.8 \%$ ), but it was much larger in the other 7 (c.t.r. 57 to $66 \%$; average $59.7 \%$ ). At least one of

TABLE III

Comparison of some Clinical Data for Patients with Solitary Trunk (II), Pulmonary Atresia (III), and FALLOT'S TETRALOGY

\begin{tabular}{|c|c|c|c|c|c|c|c|}
\hline $\begin{array}{l}\text { Grcip and No. of } \\
\text { cases }\end{array}$ & Disability & Cyanosis & $\begin{array}{l}\text { Art. } \mathrm{O}_{2} \text { satn. } \\
\text { Mean and } \\
\text { range }\end{array}$ & $\begin{array}{l}\text { Hæmoglobin } \\
\text { Mean and } \\
\text { range }\end{array}$ & $\begin{array}{l}\text { Heart size } \\
\text { (c.t.r.) } \\
\text { Mean and } \\
\text { range }\end{array}$ & $\begin{array}{c}\text { Right-sided } \\
\text { aortic } \\
\text { arch }\end{array}$ & Squatting \\
\hline $\begin{array}{c}\text { IIA (9) } \\
\text { IIB (7) } \\
\text { III (18) } \\
\text { Fallot's t. (50)* }\end{array}$ & $\begin{array}{l}2 \cdot 0^{*} \\
2 \cdot 5 \\
2 \cdot 9 \\
3 \cdot 2\end{array}$ & $\begin{array}{l}1 \cdot 8^{*} \\
2.9 \\
3 \cdot 0 \\
3 \cdot 2\end{array}$ & $\begin{array}{l}83(79-89) \\
68(65-73) \\
73 \cdot 2(67-81) \\
72 \cdot 7(47-92)\end{array}$ & $\begin{array}{l}104(92-118) \\
130(98-161) \\
127(110-148) \\
134(120-150)\end{array}$ & $\begin{array}{l}60 \cdot 2(55-68) \\
56 \cdot 0(47-62) \\
53 \cdot 6(46-66) \\
48 \cdot 8(37-61)\end{array}$ & $\begin{array}{c}5 / 9 \\
3 \frac{1}{2} / 7 \\
4 / 18 \\
1 / 4\end{array}$ & $\begin{array}{l}1 / 9 \\
2 / 6 \\
4 / 18 \\
8 / 10\end{array}$ \\
\hline
\end{tabular}

* The figures in columns 2 and 3 are the means of the Grades into which these patients were originally put.

$\dagger$ Most of these figures are taken from the first 50 patients operated on at Guy's Hospital, but the hæmoglobin figures are from 100 cases (Campbell, 1954, Table II).
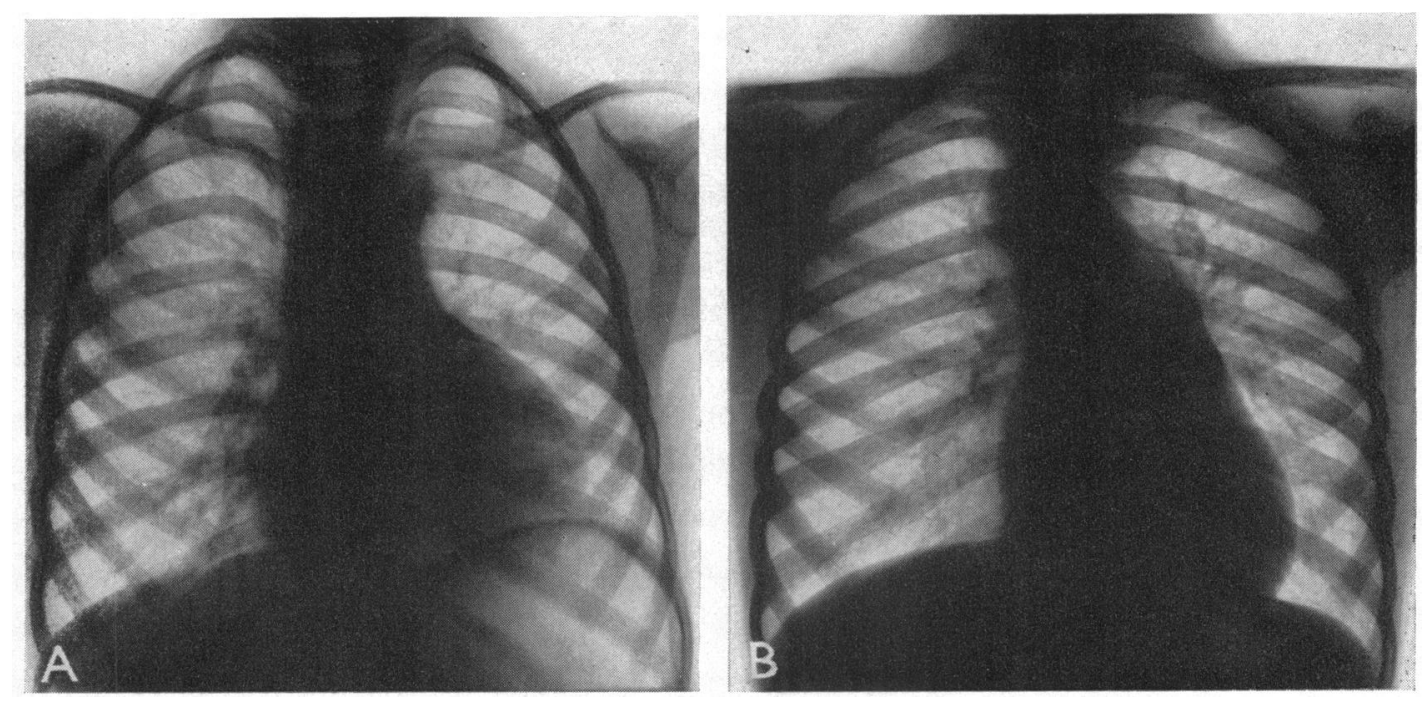

FIG. 9.- Teleradiograms of two patients with pulmonary atresia and a diminished blood flow to the lungs through bronchial arteries. (A) An enlarged heart (c.t.r., 59\%) with the usual shape of pulmonary atresia from a girl, aged 3. She was somewhat improved after an anastomotic operation. Case 31. (B) A heart of normal size (c.t.r., $49 \%$ ) with a right-sided aortic arch and an unusual shape because there was also corrected transposition of the aorta and pulmonary trunk. From a girl, aged 7, still getting on well after 12 years. Case 33 
these had additional cardiac malformations, but we do not know why the others, three of whom were proved to have pulmonary atresia only, had such large hearts. Short case reports of the 5 with necropsies follow and in these 5 the ages quoted are those at the time of death.

Case 18. A girl, aged 15, had pulmonary atresia and a closed ventricular septum with a pulmonary blood supply through a large left-sided persistent ductus (fully reported as Case 1 by Allanby et al., 1950).

Case 19. A boy, aged 5, had isolated levocardia, pulmonary atresia with a ductus on the left side, and cor biloculare (Campbell et al., 1952). There was no inferior vena cava and the blood from the lower part of the body reached the atrium through the vena azygos.

Case 20. A girl, aged 7, had pulmonary atresia with a blood supply to the lungs through bronchial arteries and an anomalous artery from the aortic sinus (Case 6, Allanby et al., 1950).

Case 21. A girl, aged 4, developed severe cyanotic attacks and died after operation. Necropsy confirmed the pulmonary atresia with a bronchial artery blood supply to the lungs: the ductus was closed.

Case 22. A boy, aged 1, had been cyanotic from birth and died after thoracotomy. He had pulmonary valve atresia with a left-sided ductus and a large high ventricular, and a smaller atrial, septal defect. In addition, the aorta was anterior to the pulmonary trunk, but the transposition was of the corrected type and of no functional importance in the presence of pulmonary atresia and a large V.S.D.

Cases 23-28, three boys and three girls, aged between 5 and 11 years all had operations from which they obtained varying degrees of improvement and were included among those reported by Campbell (1960). Neither these nor Cases 29-35 need be described individually.

\section{Fallot's Tetralogy}

Three patients (Cases 36-38) had Fallot's tetralogy and two (Cases 39 and 40) had the main features of this with additional lesions. The continuous murmur was soft and inconstant in the first three. It happened to be heard best on the right side in four patients although the aortic arch was on the left: in the fifth it was heard equally well on both sides. The first three all squatted. The degree of cyanosis and polycythæmia varied widely with a range from 101 to 154 per cent (average 120\%). As with most cases of Fallot's tetralogy there was little enlargement of the heart: the cardiothoracic ratio averaged 49 per cent in the first four, but was 59 per cent in Case 40 who had other lesions as well. Short case notes of these 5 patients follow.

Case 36. A man, aged 20, thought at first to have pulmonary atresia, had a successful pulmonary valvotomy for severe Fallot's tetralogy: he had been getting much worse with attacks of unconsciousness and the pulmonary valve was almost occluded. He has kept very well for eight years since his operation. His soft continuous murmur was thought to be due to a right-sided bronchial artery and at operation another bronchial artery was seen behind the small left pulmonary artery and was nearly as large as it.

Case 37. A girl, aged 3, had pulmonary valvotomy four years later for Fallot's tetralogy: she was improved but was still cyanotic and disabled. A soft continuous murmur was heard, generally but not at every visit, on both sides and in the back. An unusual number of smaller collateral arteries but no large bronchial arteries were seen at operation.

Case 38. A girl, aged 12, was very similar as regards her soft inconstant murmur but was not much disabled. She has got on well for 12 years and is now married with a child.

Case 39. A girl, aged 14, who had little cyanosis or disability and has got on fairly well for twelve years, had a loud and constant continuous murmur on the right side though the aortic arch was on the left. At catheterization, the aorta and the right P.A. were entered from the right ventricle and the $\mathrm{O}_{2}$ saturation in the right P.A. was higher than in the R. ventricle, showing that there was an additional $\mathrm{O}_{2}$ supply through the right-sided ductus or, more likely, some other collateral artery. The position of the catheter in the great vessels suggested that she had corrected transposition as well.

Case 40. A girl, aged 5 when she died, had complete situs inversus and was thought to have pulmonary atresia with a blood supply, mainly to the right lung, through a right-sided ductus. At catheterization, a double S.V.C. was confirmed and the large azygos vein drained into the S.V.C., suggesting that the inferior vena cava was absent. At operation there was a small right ventricle and a large left ventricle from which the aorta and the severely stenosed pulmonary trunk both arose. There was also some obstruction between the right P.A. with a good blood supply through the ductus and the left P.A. with a low pressure and flow through the almost atretic pulmonary trunk. She died soon after the thoracotomy. At necropsy, these features were confirmed and there was also a ventricular septal defect and a large atrial septal defect. 


\section{UNClassified PATIENTS}

These 5 patients seem different from each other and from those already described. Generally, it is useless to discuss complicated cases of congenital heart disease, even after investigations, unless they have come to necropsy, because there is so much that is possible and so little that is certain. Here, however, we have thought it desirable to record them shortly to give a more complete picture of all forms of cyanotic congenital heart disease with continuous murmurs.

None of these five had the X-ray picture that suggests a bronchial artery blood supply to the lungs. Four probably had a persistent ductus, though we have no proof of this, and Case 43 had a soft continuous murmur of the type that we have heard with Fallot's tetralogy when there is also a large bronchial artery. None of them gave a history of squatting. Two had isolated dextrocardia.

One of the first patients who in 1946 interested us in this syndrome with a continuous murmur was thought to have pulmonary valvar stenosis with a persistent ductus, and this was supported by cardiac catheterization (Deuchar and Zak, 1952) and proved by successful operation; but her cyanosis was only peripheral although at first it was thought to be central. Case 41 has this combination of lesions with central cyanosis.

Case 41. Pulmonary Stenosis and Persistent Ductus. A girl, aged 11, had only moderate disability and cyanosis but a large heart (Fig. 10A, c.t.r. 57\%). A loud continuous murmur was heard best on the left side (aortic arch, left-sided). On angiocardiography the large P.A. remained filled for some time and this was thought to be due to pulmonary stenosis. On catheterization the P.A. was not entered, the pressure in the right ventricle was raised, and there was a defect in the atrial septum. She was thought to have a rightto-left shunt through this defect and pulmonary stenosis with a persistent ductus. She developed tuberculosis of the lung but has made a good recovery and, now aged 23, still leads a fairly active life.
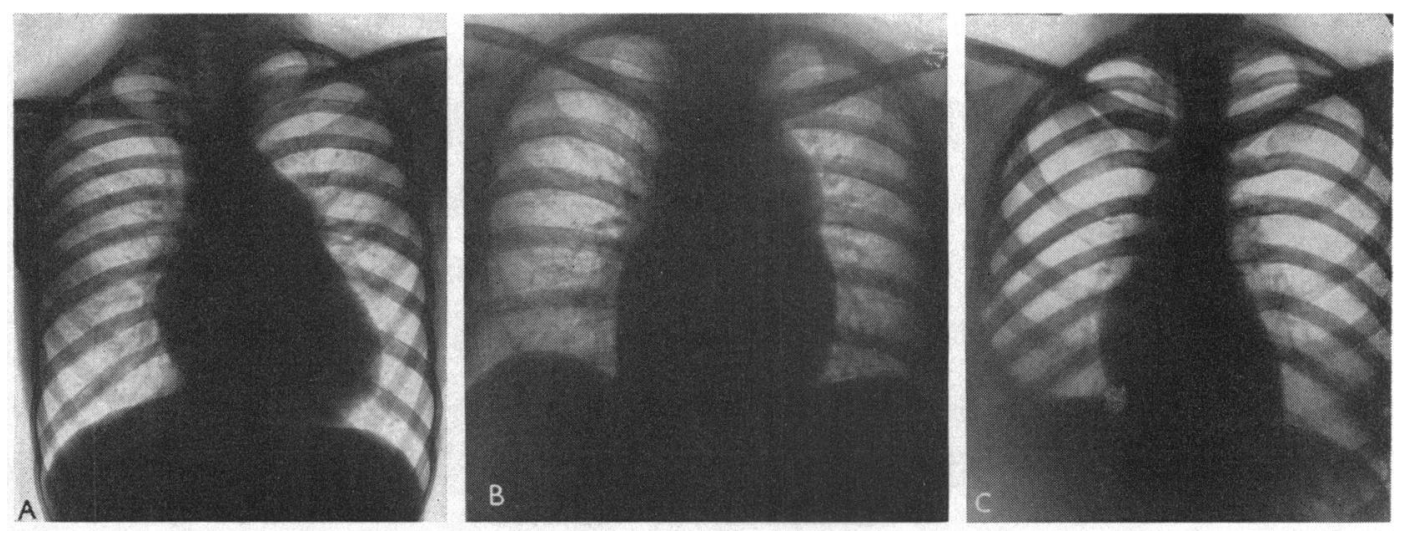

FIG. 10.-Teleradiograms from three unclassified patients. (A) From a girl, aged 11, with pulmonary stenosis and a persistent ductus. Case 41. (B) Case 42, aged 27. (C) Case 43, aged 21 . See text.

Case 42. No Diagnosis Made. A woman, aged 27, could lead a quiet life and walk a mile, though always moderately cyanosed ( $\mathrm{Hb} .133 \%$ ). A continuous murmur was heard over the left side. On radioscopy there was probably a double aortic arch, oligæmic lungs, and a large R.V. though she was the only patient without clear R.V. preponderance in the electrocardiogram. On angiocardiography, a large shadow on the left appeared to be a dilated pulmonary trunk but the lungs filled badly, the left better than the right. A catheter passed from the right to the left atrium but could not be manipulated into a ventricle. She died at home two years later but there was no necropsy.

Case 43. Diagnosis Uncertain. A girl, aged 21, had always been cyanosed (Hb. $118 \%$ ): she could earn her living and walk up to two miles but did not feel this an adequate life. She seemed to be an ordinary case of Fallot's tetralogy (Fig. 10C) with a soft continuous murmur best heard in the right axilla. At thoracotomy by Mr. Holmes Sellors, there were many small collateral arteries, a small aorta, and a large 

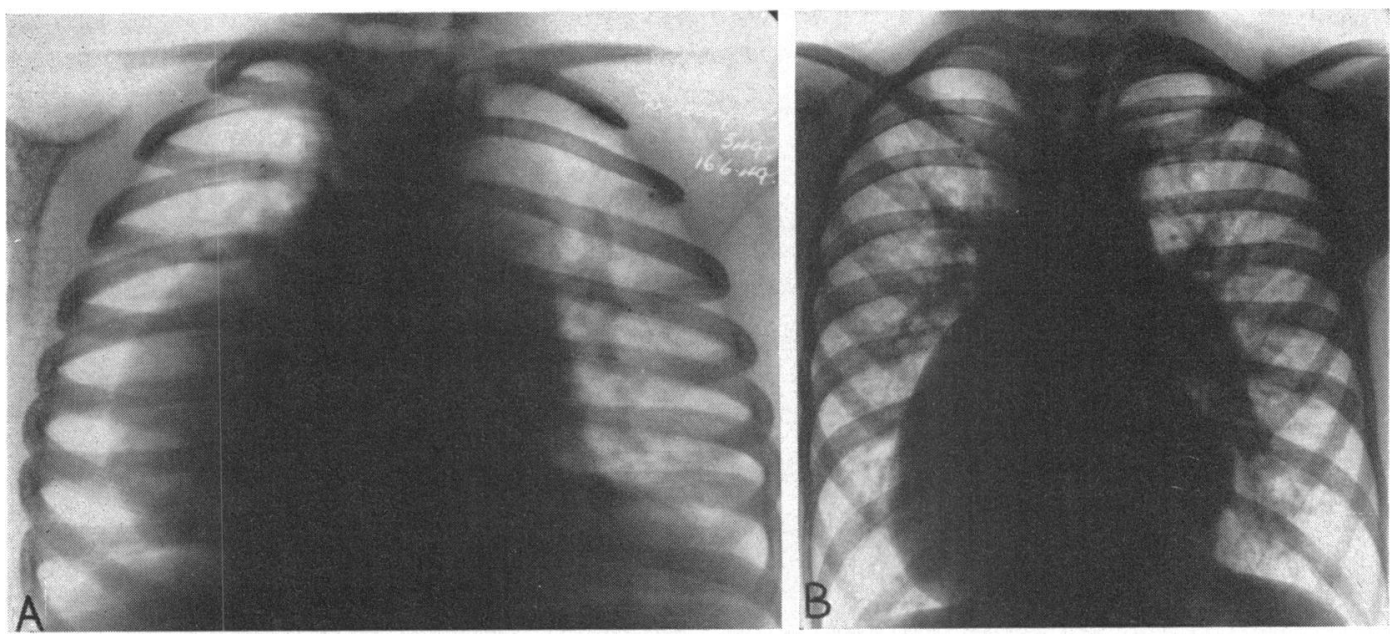

Fig. 11.-Teleradiograms from two patients with isolated dextrocardia, large hearts, and pleonæmic lungs. (A) Case 44, then aged 4. (B) Case 45, then aged 9. Both are getting on well more than ten years later. See text.

pulmonary trunk with a pressure of $56 \mathrm{~mm}$. $\mathrm{Hg}$, about the same as the aortic pressure at the time. She became very depressed that nothing had been done and died some days later. Necropsy was refused. Eisenmenger's complex was thought probable at thoracotomy but this seems to us unlikely.

Case 44. Isolated Dextrocardia. Pulmonary Hypertension. Large A.S.D. ?Single Atrium. Pleonamic Lungs. A girl, aged 3, had always been slightly cyanosed $(\mathrm{Hb}$. about $100 \%$ ) but had little disability in spite of an enormous heart (Fig. 11 ; c.t.r. $65 \%$ ). A loud continuous murmur was heard on the right side (arch on right side but arching to the right). Catheterization showed that the pressure in the ventricle and P.A. was about the same as that in the brachial artery, and the $\mathrm{O}_{2}$ saturations also were about the same76 per cent in the S.V.C., 83 per cent in the atrium, 87 per cent in the ventricle, 85 per cent in the P.A., and 84 per cent in the brachial artery. The I.V.C. was thought to be absent. She is now 14 and attends an ordinary school: she can walk 6 miles and play a little tennis.

Case 45. Isolated Dextrocardia. Cyanotic Heart Disease. ?Transposition. Pulmonary Hypertension (presumed) with Pulmonary Regurgitation. A girl, aged 9, was not much disabled or cyanosed (Hb. $91 \%$ ) though some cyanosis had been noticed since infancy and she had a large heart (c.t.r. $61 \%$ ). A loud continuous murmur that could be heard without a stethoscope was maximal on the right side (arch left-sided). The catheter entered a venous atrium, posteriorly and on the left, and passed easily to her atrium and arterial ventricle on the right. No venous ventricle could be entered; nor could the aorta or P.A. Angiocardiography showed a small venous ventricle from which the aorta appear to rise, the large P.A. filling later. She is now 20 and her condition is little changed.

\section{Discussion}

The pathological anatomy and classification of this form of congenital heart disease have been discussed earlier: here, we wish to comment on some of the clinical features.

The Continuous Murmur. In most of our patients the continuous murmur was loud or at least easily heard. The site where it was heard best varied greatly from patient to patient and sometimes from time to time, and was sometimes difficult to place precisely owing to its wide conduction. Sometimes it was heard best high under the left clavicle but not as constantly as it is with a persistent ductus. It was heard best on the right side in nearly one-third, on the left in half, and equally well on both sides in the remaining one-sixth: in many more it was conducted across to the other side and often through to the back on one or both sides. Generally, however, it was possible to say on which side the murmur was louder, and in some patients the pulmonary blood flow was obviously greater on this side.

In contrast with this, the murmur was soft and inconstant in the three patients with uncom- 
plicated Fallot's tetralogy and in one other who was undiagnosed (Case 43). We think this is the usual finding in the small number of patients with the tetralogy who have a continuous murmur. Such a murmur has been heard in less than 1 per cent of our cases with Fallot's tetralogy: some others may have been missed but not, we think, many. It is in some ways surprising that a better collateral circulation through bronchial arteries, large enough to produce a murmur, does not develop in more of the severe cases of Fallot's tetralogy where it would be so advantageous. This applies equally, though at an earlier stage, to persistence of the ductus arteriosus. We can not recollect seeing a patient with uncomplicated Fallot's tetralogy and a proved persistent ductus, but our experience is mostly with older children rather than the infants in whom Taussig thought the closing of the ductus was responsible for their deterioration or death. We have, however, seen one child with pulmonary atresia whose death just before her fifth birthday seemed to be due to the ductus closing: she is not included in this series because no continuous murmur had been heard at any of her visits to hospital.

The continuous murmur seems to be produced by the anastomosis of a bronchial artery with a branch of the pulmonary artery, in a similar way to the continuous murmur after a subclavianpulmonary anastomosis. Soulié et al. (1950) say that Routier has put forward this explanation for many right-sided continuous murmurs since 1940.

Wood (1956) states that a continuous murmur means pulmonary atresia, not persistent truncus, and that such a murmur was present in all his $\mathbf{1 5}$ cases of pulmonary atresia. This is an over simplification for a continuous murmur was heard in only half of our proved cases of pulmonary atresia. It is true that it is uncommon in the classical type of truncus arteriosus and Scott (personal communication) heard a continuous murmur in only 1 of her 20 cases in infancy. It is, however, not uncommon in the type with the pulmonary blood flow through bronchial arteries, and Taussig (1947) agrees with this.

The Side of the Aortic Arch. The aortic arch was found on the right side in 15, and on both sides in 1 , of the 45 cases-an incidence of 33 per cent which is higher than the 25 per cent found with Fallot's tetralogy.

The arch was on the right side in 8 , and was double in 1 , of the 16 cases with a solitary trunk and in the one proved case of persistent truncus. This exceptionally high incidence of over 50 per cent may be partly due to chance, but it seems probable that here a right-sided arch is more common than with Fallot's tetralogy. Collett and Edwards (1949), however, found it right-sided in only 12, and double in 1 , of the 76 cases of persistent truncus where this was clearly stated. It was rightsided in 4 of the 18 cases of pulmonary atresia, and this is about the same proportion that is found in Fallot's tetralogy.

The Relationship of the Continuous Murmur and the Side of the Aortic Arch. Where the blood flow to the lungs was through a persistent ductus ( 6 cases, all with pulmonary atresia), the murmur was heard best on the same side as the aortic arch-five times on the left side and once on the right side. This is, of course, a well-known relationship when the murmur is due to a ductus.

Although not generally recognized, there is a tendency for the same relationship to exist where the blood flow to the lungs is through bronchial or other anomalous arteries, as it was in most of these cases (Table IV). When the aortic arch was left-sided, the murmur was best heard on the left in 10 cases ( 5 with pulmonary atresia (PA) and 5 with a solitary trunk (ST)), on both sides in 4 ( 2 with PA, 2 with ST), and on the right in 2 cases (both with PA). When the arch was right-sided, the murmur was best heard on the right in 5 cases (1 with PA, 4 with ST), on both sides in 2 (both with ST), and on the left side in 4 cases ( 2 with PA, 2 with ST). In the one patient with a solitary trunk where the aorta arched to both sides, the murmur was heard best on the left although the most striking anomalous artery seen in this case on angiocardiography was on the right side. In all the six cases of Soulié et al., however, the continuous murmur was heard best on the right side, though the aortic arch was right-sided in only two of them.

In conclusion, the aortic arch was twice as likely to be on the side on which the murmur was heard best as on the other side, excluding the cases of Fallot's tetralogy. 
TABLE IV

Side of the Aortic Arch and of the Loudest Continuous Murmur when this was Produced by Bronchial ARTERIES

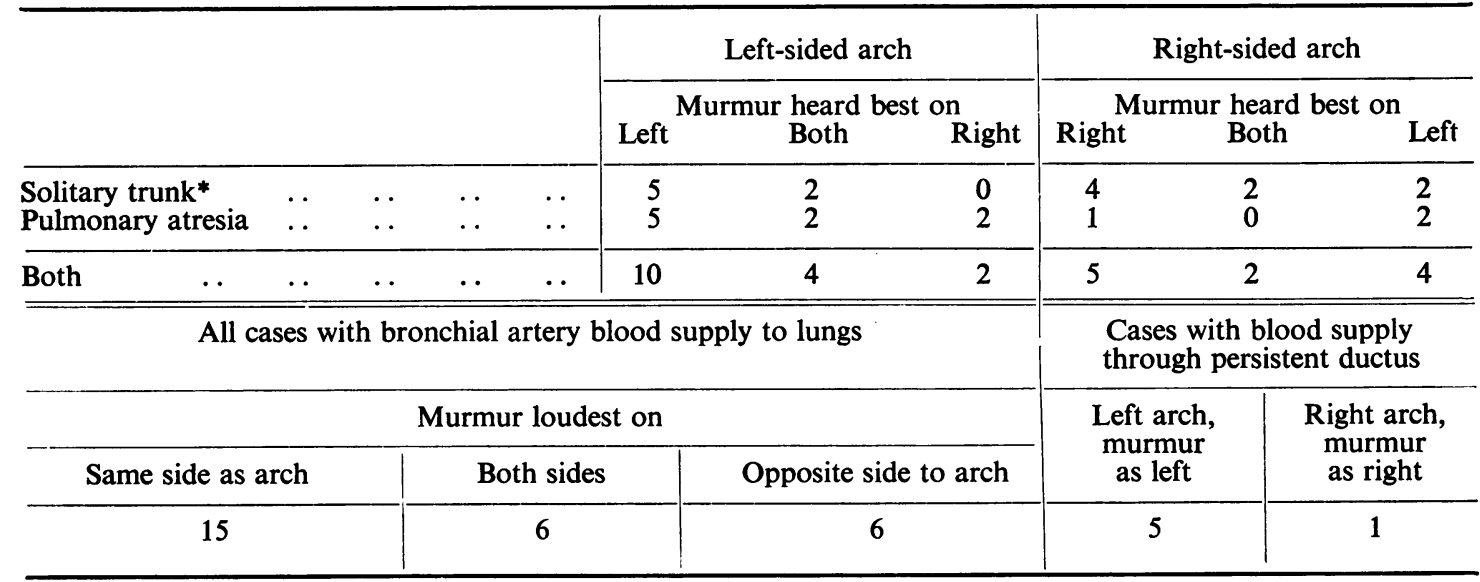

* The one case in which the arch was on both sides is not included.

Increased Pulmonary Blood through Bronchial Arteries. We have found no account of cases with a solitary trunk and an increased blood flow to the lungs through bronchial arteries, though the large blood flow through pulmonary arteries arising from a persistent truncus is well known. Wood (1956) gives clear pictures of truncus arteriosus with pleonæmic lungs and of pulmonary atresia with oligæmic lungs but not of our group where the blood flow to the lungs is moderately increased although it is through bronchial arteries. Soulié et al. (1950), however, reported six cases with radiograms and angiocardiograms very similar to ours and gave one of their reasons against surgical treatment of this group that "the pulmonary blood flow was assured by the anastomoses that had formed spontaneously."

Transposition of the main trunks has been accepted as the common cyanotic condition with an increased pulmonary blood flow, most other conditions being regarded as having a diminished flow. Both on clinical grounds and on the catheter results, several of our patients had an increased pulmonary flow. This lessens the degree of cyanosis produced by the complete mixing of the venous and arterial blood, and the larger pulmonary flow and the more active life that this allows throw more work on the heart and lead to greater cardiac enlargement. These factors help to explain why many of our patients have such a wide "aorta" and such a large heart and yet have relatively little cyanosis and disability. There is some parallel here with the large hearts and slight disability of the patient with Fallot's tetralogy who has been given a large anastomosis, so that he is much better as regards his colour and his capacity for exertion but develops a large heart.

Other Clinical Findings in Our Patients. A comparison of our Groups II and III with each other and with Fallot's tetralogy without a continuous murmur has been set out in Table III. The disability and cyanosis of the patients have been placed in the four grades that we have used for the last twelve years, e.g. I, cyanosis only on exertion; II, cyanosis not obvious at a glance; III, cyanosis obvious at a glance; and IV, severe cyanosis. The figures in the second and third columns give the average obtained by treating these grades numerically; thus, in Group IIA the cyanosis was generally not, and in Group III it generally was, obvious at a glance, and for those with Fallot's tetralogy it was rather more than this.

The degrees of disability and cyanosis rise steadily from those with a solitary trunk and an increased pulmonary blood flow (IIA) where these figures are 2.0 and 1.8 respectively to those with Fallot's tetralogy, $3 \cdot 2$ in each case. The patients with a solitary trunk and a diminished blood flow and those with pulmonary atresia are intermediate and not very different (disability, 2.5 and 2.9; 
and cyanosis, 2.9 and 3.0 respectively). Similarly, the mean hæmoglobin percentages rise regularly from 104 to 134 per cent, and the proportion with a history of squatting from 1 in 9 to 8 in 10 .

The changes in the arterial $\mathrm{O}_{2}$ saturation and in the size of the heart are in the reverse direction, the former falling regularly in each group from 83 to 73 per cent and the cardio-thoracic ratio from $60 \cdot 2$ to 48.8 per cent. These findings suggest that the pulmonary blood flow becomes progressively smaller from our Groups IIA to IIB to III and is most severe in Fallot's tetralogy-one reason why the results of an anastomotic operation are most satisfactory in this group. It is easy to understand why the heart was larger in those with an increased pulmonary flow than in those with a diminished one (c.t.r. $60 \%$ instead of $56 \%$ ); but not why it was so large in the latter and in some of our cases of pulmonary atresia, since enlargement is uncommon with Fallot's tetralogy unless there are complicating lesions, in spite of the hypertrophy of the right ventricle.

Prognosis. The prognosis was surprisingly good for our 9 patients with a solitary trunk and an increased pulmonary blood supply even though this was through bronchial arteries only and the heart was very large (Group IIA). Most of them have got on well for ten to twelve years and can do as much as when we first saw them. One woman was seen in 1955, when she was 24: she was working as a nurse and could walk five miles and is much the same after five years (Case 4). Eight were seen first in 1947-49, when one was 2, six were between 6 and 13, and one was 17 years of age: six of these have been examined in 1960 and we have heard from the doctor of the seventh: only one has not been traced. Five seem to be as well now as they were in 1948; one, the youngest, has increasing disability; and Case 9 (q.v), now 17, had an episode of heart failure recently following employment as a heavy manual labourer. Clearly, no surgical treatment that is available at present is indicated for these patients, since their blood supply to the lungs is reasonably adequate.

The 7 patients with a solitary trunk and a diminished pulmonary blood flow were more disabled and have not done so well. Four of them have died (see Table I), three in the second decade and one at the age of 30 years. Only one (Case 12) has been followed for more than ten years: she has not lost much ground so probably her pulmonary blood flow was not greatly diminished. No surgical treatment is available for these patients as there are no arteries to which an adequate anastomosis could be made.

Patients with pulmonary atresia who survive their first 7 years or so have some advantages, for atresia can not become more severe as pulmonary stenosis often does, and their pulmonary blood supply direct from the aorta can increase when the aortic blood pressure rises with exercise. We have little to add to this from our patients, since 11 of the 18 had anastomotic operations: 5 died at the time or soon after, so the operative mortality is much higher than for Fallot's tetralogy. Six are getting on well or fairly well 6 to 11 years after anastomotic operations (Campbell, 1960) and some of them would probably not have lived long without their operation. Two were never very disabled and the remaining five have not changed much.

Only a few of these cases are suitable for pulmonary valvotomy or infundibular resection when the atresia is diaphragmatic and the pulmonary trunk is patent beyond this. Those without adequate pulmonary arteries can not be helped, but there are still several who can be improved by subclavian-pulmonary anastomosis, though generally not as much as patients with Fallot's tetralogy (Campbell, 1960). It is rather surprising that they get as much improvement as they do when the lungs already obtain their blood flow direct from the aorta: clearly the bronchial or other collateral arteries have not hypertrophied as much as was desirable.

Pulmonary Atresia or Truncus Arteriosus. It is disappointing that so many of our patients have to be left with the incomplete diagnosis of solitary trunk, but the clinical distinction between pulmonary atresia and truncus arteriosus is often impossible. Of our proved cases with necropsy, the majority ( 5 cases) had pulmonary atresia and only 1 had truncus arteriosus. This seems to be true of reported cases. The only patient of Soulié et al. (1950) with a necropsy had pulmonary atresia: the bronchial arteries were larger than the small peripheral portions of the pulmonary arteries with which they anastomosed. Roche (1953), reporting three cases of cyanotic heart disease with continuous murmurs, thought these were generally due to broncho-pulmonary anastomoses 
in cases of pulmonary atresia, and this was proved by necropsy in one. Wheeler and Abbott (1928) also accepted one unusual case as pulmonary atresia: a small persistent ductus from a right-sided aortic arch joined a small right pulmonary artery, but there was also an incomplete left aortic root from which the main blood supply to the lungs arose through bronchial arteries.

Truncus Arteriosus. Little has been published about the clinical findings in patients with P.T.A who have passed infancy. All authors are agreed about the bad prognosis. Abbott (1932) found 25 examples among her 1000 cases of cardiac malformations: the average age at death was 4 years, and only one patient had lived for 25 years. Most of the 13 cases reviewed by Humphreys lived only for some weeks or months and only one survived to adult life: on the other hand, four of those she classified as solitary arterial trunk lived for between 18 and 33 years. Keith et al. (1958) found that three-quarters of 89 personal and reported cases died in the first six months, and Taussig (1947) agreed that most babies die within the first ten days of life, generally with heart failure. This poor prognosis explains why there are few cases in most clinical series.

When the pulmonary arteries arise directly from the truncus, the lungs are pleonæmic and the patient is little, if at all, cyanosed. Marshall (1943), however, reported a case of this type, a boy aged 13 when he died, who had been cyanotic from birth, perhaps because the vascular resistance in the lungs had never fallen enough to allow a large pulmonary flow. The importance of the pulmonary resistance in influencing the amount of the pulmonary blood flow and, therefore, the degree of cyanosis has been emphasized by Wood (1956).

By contrast, Taussig (1947) thought that much cyanosis suggested the alternative type with the blood supply to the lungs through bronchial arteries, but her discussion of this type seems to be based largely on a single case that was complicated by having a single ventricle. Brown (1950) states that generally a loud second sound that is single in the pulmonary area is the only helpful auscultatory sign but this is found with pulmonary atresia also and with some forms of transposition of the great vessels: often the cardiac silhouette, which he compares with a sitting duck, is the most characteristic sign.

Cases with Multiple Defects: Absent Inferior Vena Cava. Some of our patients had multiple defects and this was specially so in the small unclassified group. Two had corrected transposition (Cases 22 and 39). Dextrocardia was more common than would be expected by chance for Case 40 had situs inversus, Cases 27, 44, and 45 isolated dextrocardia, and Case 19 isolated lævocardia and cor biloculare.

It is curious that three of these last five had an absent inferior vena cava (I.V.C) with the circulation from the lower half of the body reaching the heart through an azygos vein (see Table V). In

TABLE V

Cases with Absence of the Inferior Vena Cava

\begin{tabular}{|c|c|c|}
\hline Case No. & $\begin{array}{c}\text { Sex and } \\
\text { age }\end{array}$ & Other malformations \\
\hline $\begin{array}{r}19 \\
40 \\
44 \\
P 180\end{array}$ & $\begin{array}{l}\text { M5† } \\
\text { F5 } \\
\text { F } 3-14 \\
\text { M }^{2} / 12 \dagger\end{array}$ & $\begin{array}{l}\left.\text { Isolated lævocardia, pulmonary atresia, and cor biloculare (Case } 4^{*}\right) \\
\left.\text { Situs inversus and severe pulmonary stenosis (Case } 5^{*}\right) \\
\text { Isolated dextrocardia and pleonæmic lungs }\left(\text { Case } 7^{*}\right) \\
\text { Isolated dextrocardia, pulmonary stenosis, single atrium, and common A-V } \\
\left.\text { valve (Case } 6^{*}\right)\end{array}$ \\
\hline
\end{tabular}

* Case numbers in Campbell and Deuchar, 1954.

$\dagger$ With necropsy proof.

Case 44 the catheter in the right saphenous vein passed up the left side, through an azygos vein, and then down a left S.V.C. into a left-sided atrium; presumably there was no I.V.C. In Cases 19 and 40 the diagnosis was confirmed by necropsy.

We have previously reported four cases of this type, when describing a series of patients with a left-sided superior vena cava. One with isolated dextrocardia died when two months old and the 
others (Cases 4, 5, and, 7 of Campbell and Deuchar, 1954) are the three included here. We have seen other examples of this condition, but only these three had a continuous murmur: this was proved to be due to a persistent ductus in two and was thought to be in the third. Obviously there is no direct connection between the persistent ductus and the absent I.V.C.- only the fact that the patients concerned have complex lesions made up of several separate malformations.

This curious syndrome, where the I.V.C. is absent and the blood from the lower half of the body, apart from the portal and hepatic veins, reaches the heart through a large azygos vein and the right or left S.V.C., is not extremely rare but does not seem to be widely recognized. All our four original cases had complete or partial transposition-situs inversus in one, isolated lævocardia in one, and isolated dextrocardia in two. It seems that partial or complete transposition is one factor in the production of this syndrome, probably because it makes it more difficult for a venous system that was originally bilateral and symmetrical to develop into an inferior vena cava that is unilateral and therefore asymmetrical.

\section{Summary AND Conclusions}

We have discussed the diagnosis, clinical picture, and prognosis in 45 patients with cyanotic congenital heart disease and a continuous murmur. The murmur was loud in 40 and soft and variable in 5 of them: it was due to a persistent ductus in one-quarter and to a bronchial artery blood supply to the lungs in three-quarters.

In 35 of the 45 patients, there was a single arterial trunk that carried the blood from both ventricles. When there is such a trunk and a pulmonary blood supply through bronchial arteries, it is often impossible to make the clinical distinction between persistent truncus arteriosus and pulmonary atresia: we have classified such patients as having a solitary trunk. In all these there is a continuous range from patients with a reduced pulmonary blood flow, a heart that is not much enlarged, moderate cyanosis, and considerable disability (the classical and commoner picture of pulmonary atresia) to those with an increased pulmonary blood flow, a large heart, slight cyanosis, and relatively little disability until heart failure supervenes (the classical and commoner picture of persistent truncus in infancy).

Of the 45 patients, 1 had a persistent truncus, 16 had a solitary trunk, and 18 had pulmonary atresia: 5 of the remaining 10 had Fallot's tetralogy or a related condition and the last 5 could not be classified.

Of the 16 patients with a solitary trunk, 9 had an increased blood flow to the lungs, although this was through bronchial arteries-a condition that has not been widely recognized (our Group IIA). Corresponding to this, they were less disabled and cyanosed and had less increase in their hæmoglobin than most patients with Fallot's tetralogy or pulmonary atresia, they did not squat, and had little or no clubbing of the fingers (see Table III). Most of them have got on well for 12 years and are now near the end of their second decade. No surgical treatment is indicated for such patients at present.

In general, squatting was much less common than with Fallot's tetralogy. It occurred in 3 of the 5 patients who were placed in the Fallot group but in only 7 of the other 40 -in 3 of the 17 with a solitary trunk and in 4 of the 18 with pulmonary atresia.

The aortic arch was right-sided in rather more than half of those with a solitary trunk, and in about a quarter of the patients with pulmonary atresia, this being about the same proportion in pulmonary atresia as in Fallot's tetralogy.

The pulmonary blood flow was through bronchial arteries in all the patients with a solitary trunk and in about two-thirds of those with pulmonary atresia: in the remaining third it was through a persistent ductus. The continuous murmur was generally loudest on the same side as the aortic arch, even when the flow was through bronchial arteries.

Several of the patients had other malformations of the heart, the commonest being some form of transposition of the viscera-situs inversus in 1, isolated dextrocardia in 3 , and isolated lævocardia in 1 . There were 3 patients among these 5 who had no inferior vena cava and a blood flow from the 
lower half of the body through the azygos vein-an interesting syndrome that is not widely recognized.

We should like to thank Dr. Frances Gardner for help in the investigation of several of these patients in 1948-50 and for many discussions about them.

\section{REFERENCES}

Abbott, M. E. (1936). Atlas of Congenital Cardiac Disease. American Heart Association, New York. Allanby, K. D., Brinton, W. D., Campbell, M., and Gardner, F. (1950). Guy's Hosp. Rep., 99, 110.

Brotmacher, L., and Deuchar, D. C. (1956). Clin. Sci., 15, 441.

Brown, J. W. (1950). Congenital Heart Disease. 2nd ed., Staples Press, London.

Campbell, M. (1954). Brit. Heart J., 16, 275.

- (1958). Brit. Heart J., 20, 260.

(1960). Brit. Heart J., 22, 527.

- and Hills, T. H. (1950). Brit. Heart J., 12, 65.

- and Gardner, F. (1950). Brit. Heart J., 12, 183.

—, Gardner, F., and Reynolds, G. (1952). Brit. Heart J., 14, 317.

, and Deuchar, D. C. (1954). Brit. Heart J., 16, 435.

Collett, R. W., and Edwards, J. E. (1949). Surg. Clinics N. Amer., 29, 1245.

Deuchar, D. C., and Zak, G. A. (1952). Guy's Hosp. Rep., 101, 1.

Gardner, Francis (1952). 1er Congrès Mondial de Cardiologie. Paris, 1950. Communications, Tome III. J. B. Baillière et fils, Paris.

Humphreys, Eleanor, M. (1932). Arch. Path., 14, 671.

Keith, J. D., Rowe, R. D., and Vlad, P. (1958). Heart Disease in Infancy and Childhood. Macmillan Co., New York. Marshall, R. (1943). Brit. Heart J., 5, 194.

Roche, E. H. (1953). Austral. Ann. Med., $2,17$.

Soulié, P., Nouaille, J., Schweisguth, O., and Touche, M. (1950). Bull. Soc. Méd. Hôp., Paris, 19, and $20,919$.

Taussig, Helen, B. (1947). Congenital Malformations of the Heart. Commonwealth Fund, New York.

Vierordt, H. (1898). In Nothnagel's Specielle Pathologie und Therapie. Wien, Vol. 15, 132.

Whyller, D., and Abbott, M. E. (1928). Canad. med. Ass. J., 19, 297.

Wood, P. (1956). Diseases of the Heart and Circulation. 2nd ed., Eyre and Spottiswoode, London. 